\title{
Strategies to prevent injury in adolescent sport: a systematic review
}

\author{
Liz Abernethy, Chris Bleakley
}

Br J Sports Med 2007;41:627-638. doi: 10.1136/bjsm.2007.035691

This systematic review set out to identify randomised controlled trials and controlled intervention studies that evaluated the effectiveness of preventive strategies in adolescent sport and to draw conclusions on the strength of the evidence. A literature search in seven databases (Medline, SportDiscus, EMBASE, CINAHL, PEDro, Cochrane Review and DARE) was carried out using four keywords: adolescent, sport, injury and prevention (expanded to capture any relevant literature). Assessment of 154 papers found 12 studies eligible for inclusion. It can be concluded that injury prevention strategies that focus on preseason conditioning, functional training, education, balance and sport-specific skills, which should be continued throughout the sporting season, are effective. The evidence for the effectiveness of protective equipment in injury prevention is inconclusive and requires further assessment.

See end of article for authors' affiliations

Correspondence to: Dr Liz Abernethy, Physicians Office, W3A

Withers Orthopaedic Unit,

Musgrave Park Hospital,

Belfast BT9 7JR, UK;

liz.abernethy@

btopenworld.com

Accepted 19 April 2007

Published Online First

31 May 2007
S port is the main cause of injury in adolescents. ${ }^{12}$ Young people are at particular risk of sports injury because of high levels of exposure at a time of major physiological change. $^{3} 4$ Prevention of injury is important for several reasons not least the initial impact on health and long-term outcome-that is, early development of osteoarthritis. ${ }^{5}$

Although most sports injuries are not severe enough to require hospitalisation, they are frequent and have a major economic impact through direct medical costs, treatment and rehabilitation, and indirect costs, including parents taking time off to care for injured offspring. ${ }^{26}$ In addition, injury prevents future involvement in physical activity, and about $8 \%$ of adolescents drop out of recreational sporting activities annually because of injury. ${ }^{7}$ There are long-term public health consequences associated with inactivity in terms of cardiovascular disease, obesity, etc, but injury may also interfere with the potential benefits of greater self-esteem, relaxation, socialisation, teamwork and fitness associated with sport participation at this age. ${ }^{8}$

Injury prevention generally focuses on modifiable risk factors: extrinsic factors, such as equipment, playing surface, rule changes and playing time, or intrinsic factors, such as fitness, flexibility and balance. This is based on adult research, but is now supported by studies of sports injury prevention in children and adolescents.

There are few systematic reviews of sports injury prevention in adolescents, ${ }^{6}$ and none focusing specifically on the adolescent age group. The aim of this review is to examine prevention strategies in adolescent sport, focusing specifically on sports that are available in schools. The specific objectives of this systematic review are:

- (a) To identify randomised controlled trials and controlled intervention studies that evaluate the effectiveness of preventive strategies in adolescent sport.

- (b) To make conclusions on the strength of the evidence supporting methods used to prevent injury.

\section{METHODS}

\section{Search strategy and selection of studies}

Relevant studies were identified using a computerbased literature search in seven databases (Medline 1966-January 2006, SportDiscus, EMBASE (1974January 2006), CINAHL (1982-January 2006), PEDro and Cochrane Databases: Cochrane Review and DARE) using four keywords: adolescent, sport, injury and prevention. These keywords were expanded to capture any relevant literature:

- (1) Adolescent OR youth OR (high+school+student) OR school age OR school+pupil

(2) Injury

- (a) wounds AND injuries exp.

- (b) sport\$ injur\$ OR athletic\$ injur\$

- (c) sprain\$ OR strain\$ OR twist\$ OR tear\$ OR pull OR break\$ OR fracture\$ OR

- (d) soft tissue injur\$ Or acute injury

- (e) chronic injur\$ OR overuse injury OR cumulative trauma OR repetitive trauma OR tendonitis OR tendinopathy

- (f) concussion OR head injury

- (g) major trauma OR catastrophic injury OR death

- (3) Sport

- (a) explode sports

- (b) sport\$ OR exercise OR athletic\$ OR physical education OR school games

- (c) hockey OR rugby OR football OR soccer OR swim\$ OR tennis OR squash OR badminton OR basketball OR netball OR Gaelic football OR GAA OR camogie OR hurley OR hurling

Abbreviations: $A C L$, anterior cruciate ligament; NNT, number needed to treat 
(4) Prevention

- (a) primary+prevention

- (b) protective+equipment OR protective device OR safety device OR taping OR brace\$

- (c) supervision OR rule enforcement OR rule change\$ OR competition+rules

- (d) sport\$+facilities OR sport\$+grounds

- (e) size+matching OR age-matching

- (f) warm-up OR warm-down OR pre-season+preparation OR pre-season+training OR resistance+training OR weight+training OR strength+training. The Cochrane Filter was applied.

In the first stage of selection, the titles and abstracts of all studies were assessed for the criteria below. Full text articles were retrieved for potentially relevant studies where no abstract was available, where the cohort age was unclear from the abstract, and where the abstract suggested selection. There was no blinding to study author, place of publication or results. Hand searches of study bibliography identified a further 62 potentially relevant publications that were subsequently retrieved and assessed. The primary reviewer (LA) assessed the content of all full text articles, making the final inclusion/ exclusion decisions on the basis of criteria described below.

\section{Selection criteria} Types of study

Randomised controlled trials, non-randomised intervention studies and cohort studies, published in English, were considered.

\section{Types of participants}

Adolescents (12-18 years) involved in supervised physical education and sport. This includes the usual range of school sports in Ireland (athletics, hockey, rugby, football, swimming, tennis, squash, badminton, basketball, handball, netball, gaelic football, camogie, hurling and lacrosse). It excludes sports that only a minority have the opportunity to experience-for example, equestrian sport, water sports, snow boarding, skiing, ice hockey, skating and motorised sport. It excludes unsupervised sports-for example, roller-blade and skate sports-and "extreme sport" activities. Both acute (fractures, soft-tissue injuries, concussion, head injuries, major trauma, death) and chronic injuries were included. Studies that included both adult and adolescent participants were included if the adolescent age group could be identified and studied separately.

\section{Types of intervention}

Studies examining the effect of any preventive interventionfor example, protective equipment, specialist coaching, conditioning or neuromuscular training-were included. Control interventions included no intervention or other interventions.

\section{Types of outcome measured}

Injury was the outcome measured and defined as:

- (1) Injury rate (per participant, per 1000 exposures or per 1000 exposure hours).

- (2) Injury severity (time missed from sport participation, training practice or match because of injury).

- (3) Where possible, individual study effect estimates were calculated-that is, risk ratios (RR) each with 95\% CI. ${ }^{9}$

Note that recording of injury by participants or observers was acceptable for inclusion purposes.

\section{Validity assessment}

The two authors (LA and CB) independently assessed the methodological quality of each study. We were not blinded to the identity of authors, institutions and journals. Agreement was reached by consensus regarding the methodological quality of all studies. As no validated tools exist to evaluate or rate studies that are not randomised controlled trials, we developed a quality assessment key to score the studies (table 1). This key was based on keys used by the Cochrane Collaboration Injuries Group and the Cochrane Collaboration Bone, Joint and Muscular Trauma Group. We piloted the key independently, modified it by consensus, and used it to score all included studies. For the purposes of this review, studies were rated for quality by application of a system described by MacKay et $\mathrm{al}^{6}$ whereby a score for overall quality was converted into a percentage value-that is, $0-49 \%$ is poor, $50-89 \%$ moderate, and $>90 \% \operatorname{good}($ table 2 ).

\section{Data extraction}

We (LA, CB) independently extracted data on the study characteristics, study population, interventions, analyses and outcome. Studies were first assessed for homogeneity with respect to the nature of the intervention, control group, and the type and timing of outcomes and follow-up.

Table 1 Study quality score key

Study reference:

Score

How was allocation to the intervention group done?

$2=$ random

1 = cluster random

$0=$ historical comparison/volunteer or convenience group

Was the assigned intervention concealed before allocation?

2 = adequate

$1=$ unclear

$0=$ inadequate/impossible

Were the outcomes of participants who withdrew described and included in the analysis (intention to treat/effect of compliance)?

$2=$ withdrawals well described and accounted for in analysis

$1=$ withdrawals described and analysis not possible

$0=$ no mention, inadequate mention, or obvious differences and no adjustment

Were the outcome assessors blinded to treatment status?

$2=$ effective action taken to blind assessors

$1=$ small or moderate chance of unblinding of assessors

$0=$ not mentioned or not possible

Were the inclusion and exclusion criteria (age, previous injury, sport) clearly defined?

2 = clearly defined

1 = inadequately defined

$0=$ not defined

Were the intervention and control group comparable at entry?

2 = good comparability of groups, or confounding adjusted for in analysis

1 = confounding small; mentioned but not adjusted for

$0=$ large potential for confounding, or not discussed

Were the interventions clearly defined?

2 = clearly defined interventions are applied

1 = clearly defined interventions are applied but the application is not standardised

$0=$ intervention and/or application are poorly or not defined

Were the outcome measures used clearly defined? (injury: selfreported injury/medically confirmed/severity defined)

2 = clearly defined

$1=$ adequately defined $/$ recorded

$0=$ not adequately defined $/$ recorded

Was the surveillance period active and of clinically appropriate duration?

2 = active surveillance and appropriate duration

1 = active surveillance, but inadequate duration

$0=$ surveillance not active or not defined

Total score $(18=100 \%)$ 


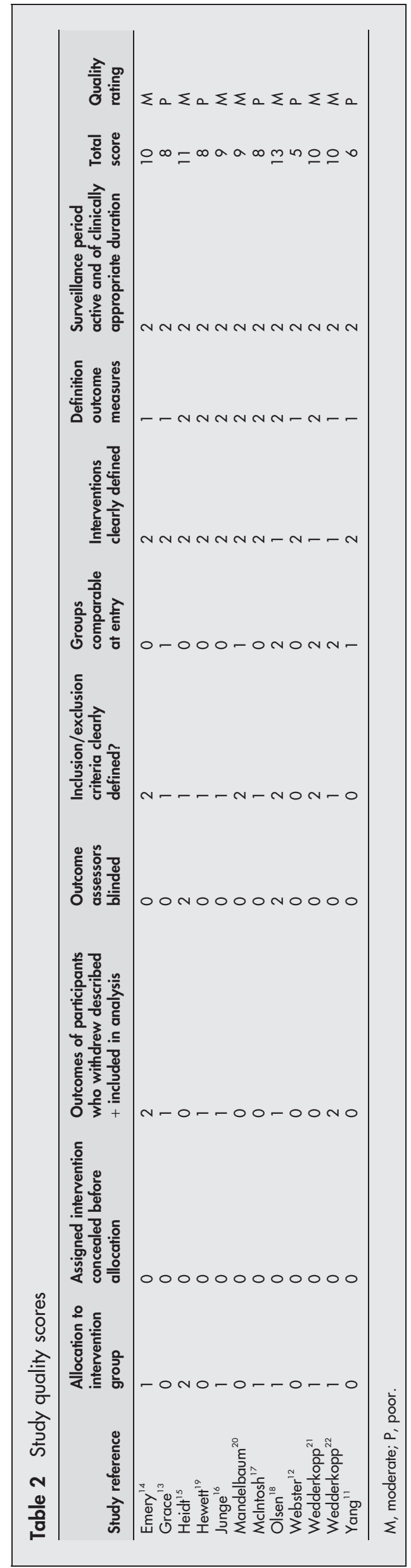

Study characteristics

Tables 3-5 summarise the study characteristics.

\section{Quantitative data synthesis}

Table 6 gives quantitative data synthesis with results.

\section{RESULTS}

Trial flow

The process of study selection and explanations of exclusions at each stage are reported according to the Quality of Reporting of Meta-Analysis (QUORUM) statement flow diagram ${ }^{10}$ (fig 1). From the initial list of citations yielded in the literature search, 154 studies were included. After review of the complete texts, 142 studies were excluded, leaving 12 eligible studies for inclusion in this review.

\section{Study characteristics}

Injury-prevention studies fell into two groups: the effect of use of protective equipment; the effect of preseason conditioning programmes and injury-prevention strategy that continued throughout the season. Results will be discussed in these study groupings.

\section{Outcome measures}

The definition of injury varied across studies. In certain cases "injured subjects" could still have been actively involved in their sport; for example, Yang et al ${ }^{11}$ used the definition "any new injury that required medical attention or restricted participation on the day after the injury", whereas Webster et $a l^{12}$ used the definition "any injury involving the head or face", and Grace et $a l^{13}$ used the simple definition "any lower limb injury that limited participation". In the majority of studies, ${ }^{14-18}$ however, only subjects that missed one or more days' participation in sport were described as sustaining an injury. Two studies ${ }^{19}{ }^{20}$ focused solely on the incidence of knee injuries, with one ${ }^{19}$ counting only knee injuries significant enough to seek care from an athletic trainer and leading to $>5$ days lost time from practice. Mandlebaum et al ${ }^{20}$ focused on anterior cruciate ligament (ACL) injuries, using diagnostic confirmation from MRI and arthroscopy.

The methods used to collect injury data and verify the injury lacked consistency. In the majority, athletes subjectively reported their injury, by using questionnaires or by relaying information to a nominated reporter, coach, investigator, physiotherapist, nurse or doctor. Only half of the studies followed up subjective reports with a physical examination by a doctor, physiotherapist or athletic trainer, ${ }^{13} 1617192122$ and only one study opted to use further diagnostic imaging. ${ }^{20}$

\section{Protective equipment}

Four studies ${ }^{11-13} 17$ monitored the benefits of various forms of protective equipment throughout a range of sporting environments. All of these studies achieved a poor rating on quality score $(<50 \%)$. A 2 -year study ${ }^{13}$ found that hinged knee braces were not effective at reducing knee injury in high school American footballers, and were even associated with an increase in ipsilateral ankle and foot injuries. A larger study by Yang et al ${ }^{11}$ using athletes from 12 different sports also found that both knee and ankle braces increased lower limb injury rates, but the use of knee pads was associated with a significant reduction. McIntosh and McCrory $^{17}$ found that headgear (scrum caps) could not reduce the incidence of concussion occurring in junior rugby union players over a single playing season, whereas the cohort study of Webster et $a^{12}$ on lacrosse players over two seasons found that eye goggles reduced the number of head and face injuries, particularly during competition. 


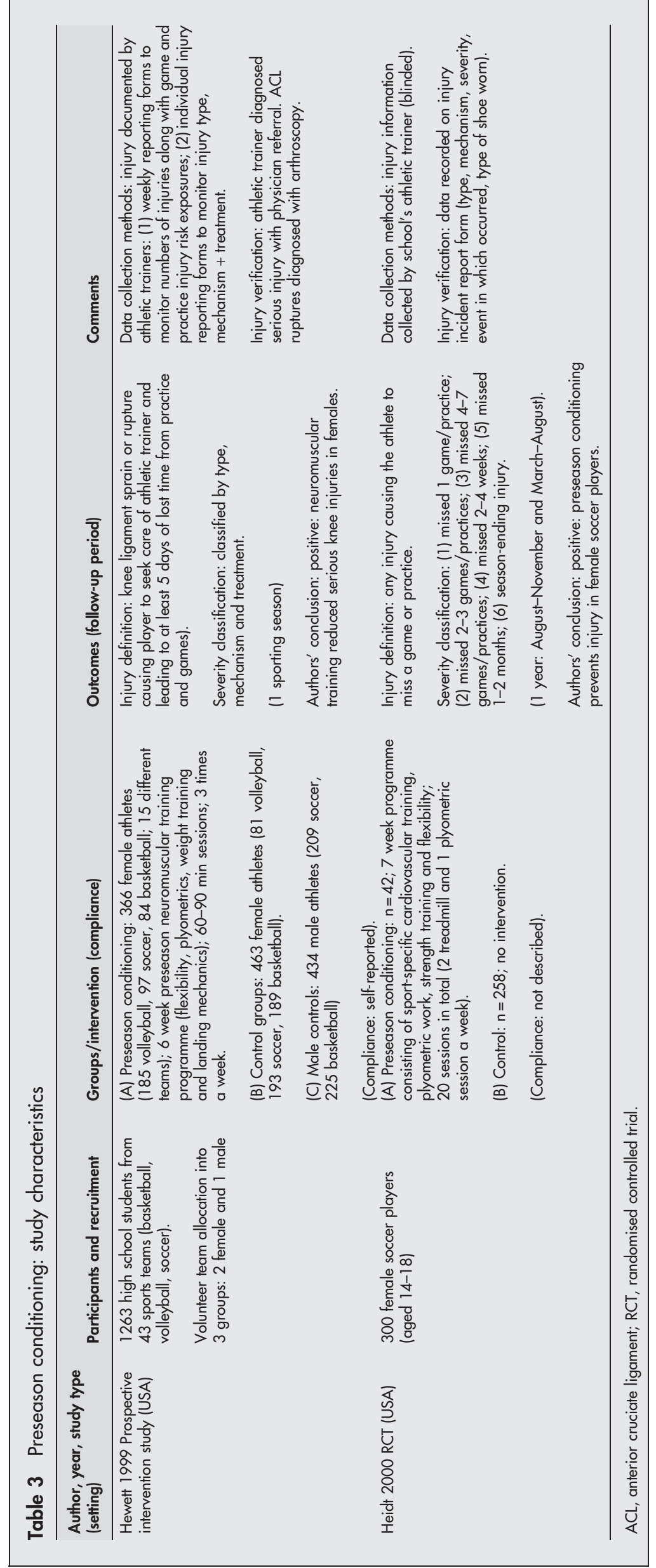




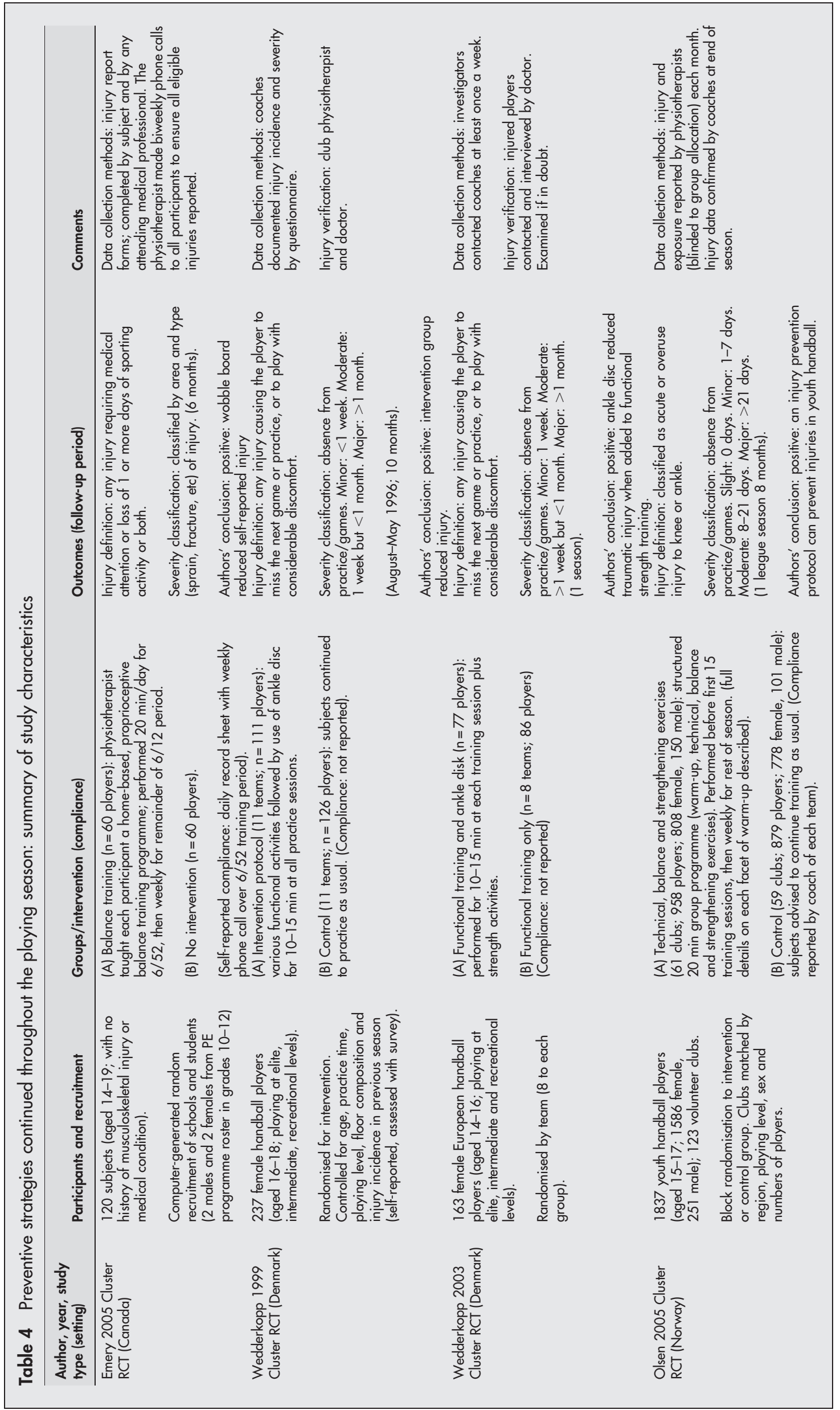




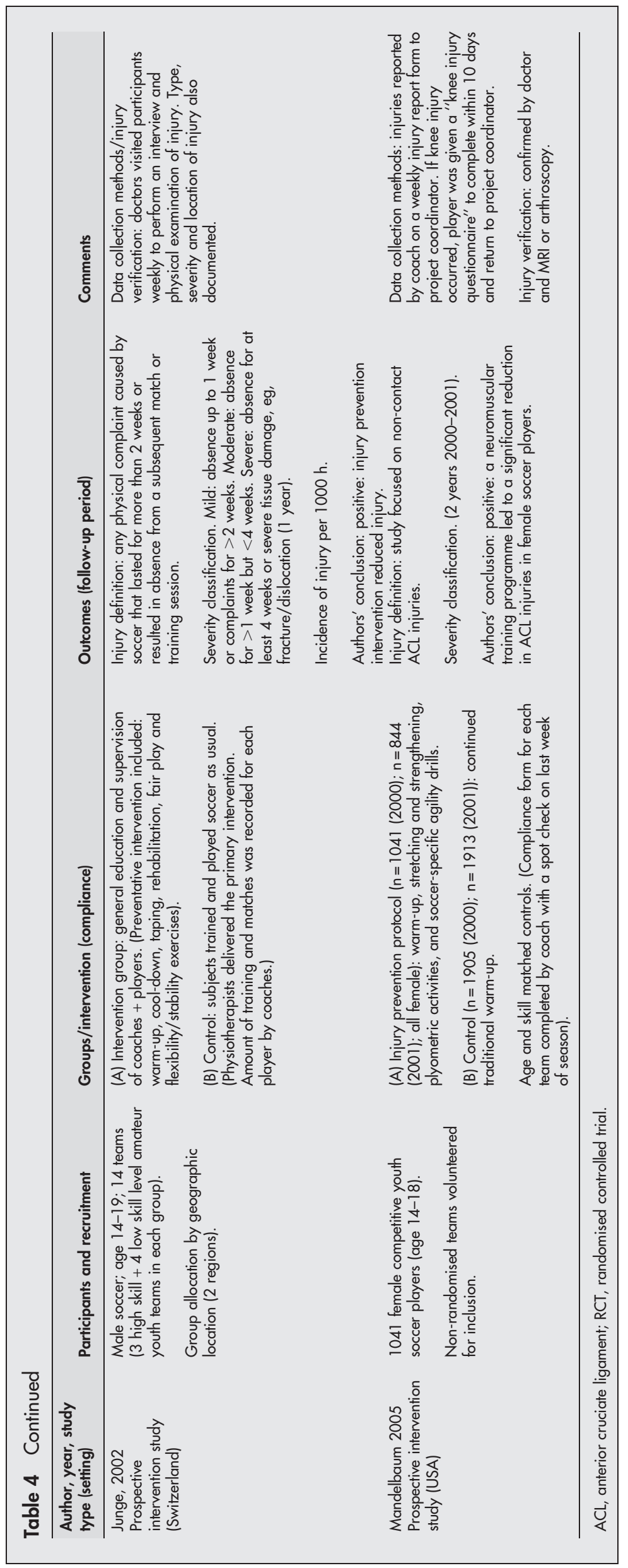

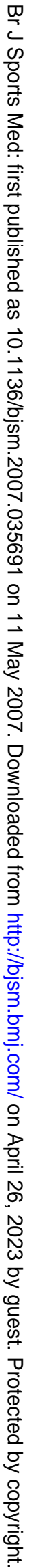



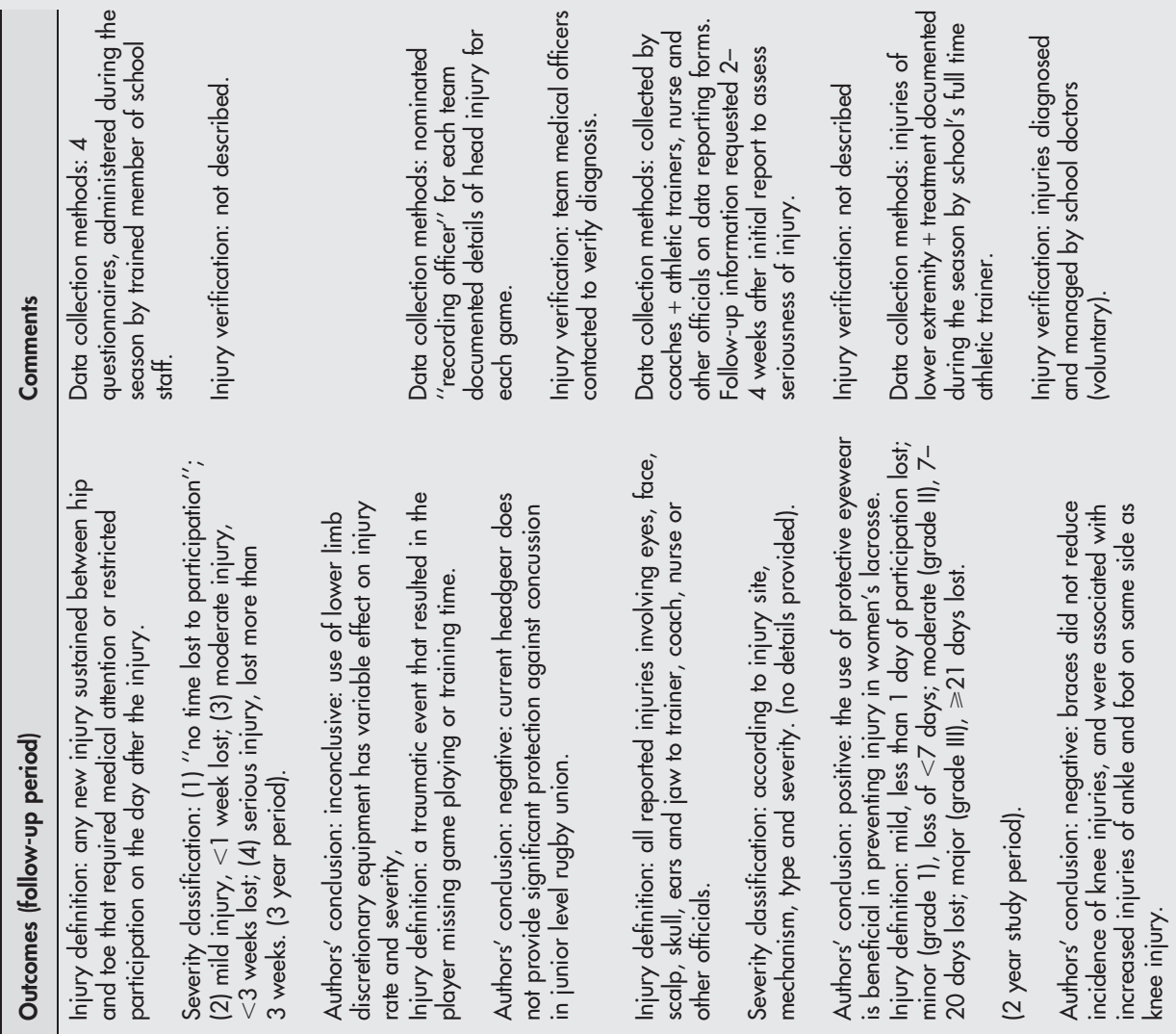

혼.
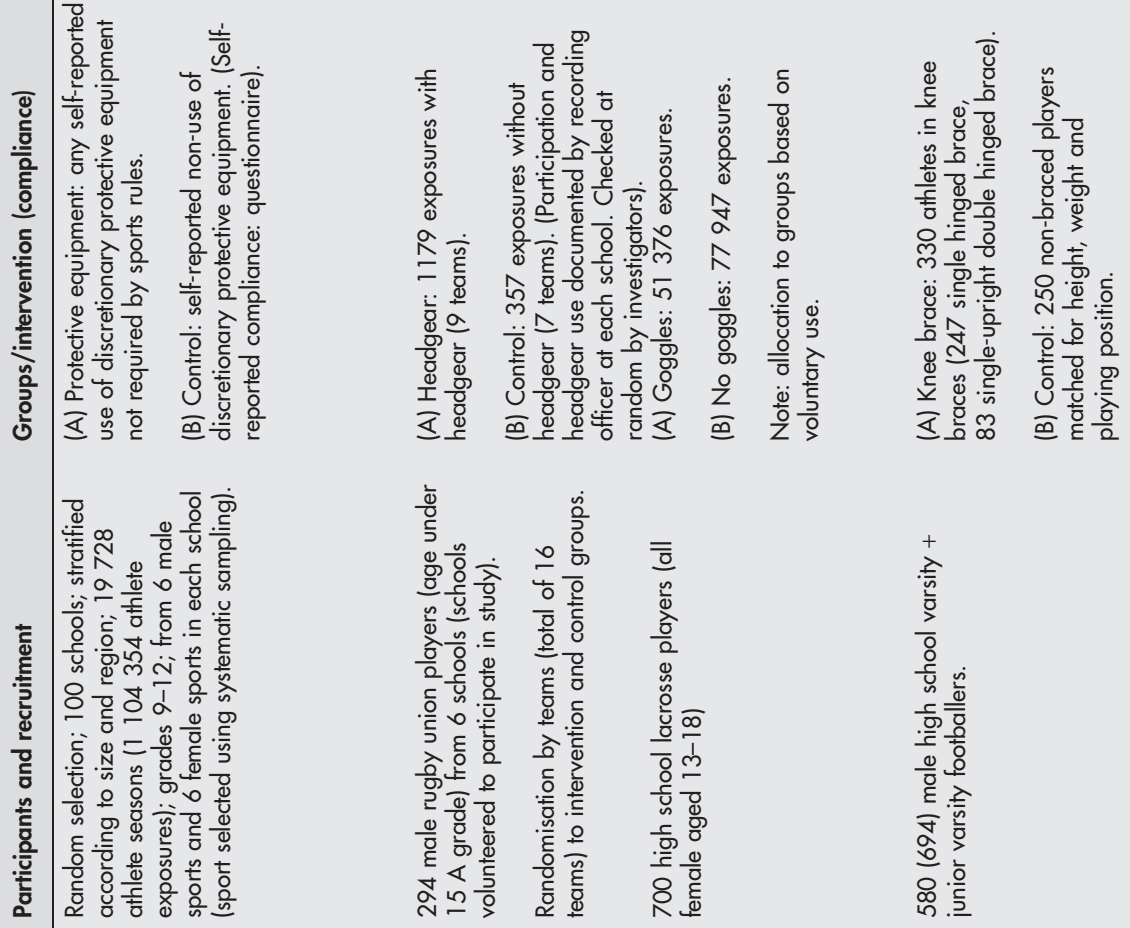

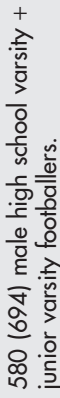
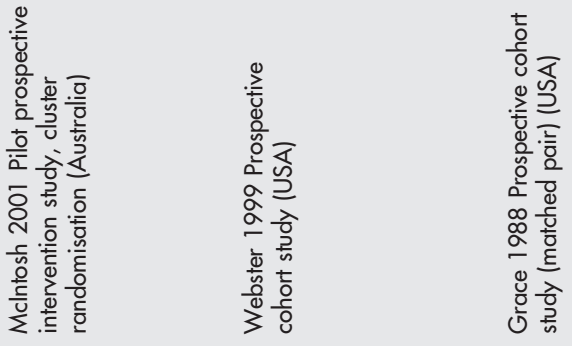
Table 6 Summary of study results

\begin{tabular}{|c|c|c|c|c|c|c|c|}
\hline First author & Sample size & Outcome measured & $\begin{array}{l}\text { Injuries in } \\
\text { intervention } \\
\text { group (A) }\end{array}$ & $\begin{array}{l}\text { Injuries in } \\
\text { control } \\
\text { group (B) }\end{array}$ & $\begin{array}{l}\text { Injury reduction } \\
\text { (RR }(95 \% \mathrm{CI}) \text { ) }\end{array}$ & $\begin{array}{l}\text { Absolute risk } \\
\text { reduction }\end{array}$ & NNT \\
\hline Emery & 114 & Self-reported injury & 2 & 10 & 0.2 (0.03 to 0.72 ) & $-0.19(19 \%)$ & 5 \\
\hline Jung & 194 & $\begin{array}{l}\text { Injury per player } \\
\text { per year } \\
\text { Injury per } 1000 \mathrm{~h} \\
\text { exposure }\end{array}$ & $\begin{array}{l}0.76 \\
6.71\end{array}$ & $\begin{array}{l}1.18 \\
8.48\end{array}$ & 0.73 & $-0.195(19 \%)$ & 6 \\
\hline Mandlebaum & $\begin{array}{l}2943 \\
2757\end{array}$ & $\begin{array}{l}\mathrm{ACL} \text { injury rate per } \\
\text { athlete/1000 } \\
\text { exposures/year }\end{array}$ & $\begin{array}{l}0.05 \\
0.13\end{array}$ & $\begin{array}{l}0.47 \\
0.51\end{array}$ & 0.255 & $-0.18(18 \%)$ & 6 \\
\hline Olsen & 1837 & $\begin{array}{l}\text { Number (\%) of } \\
\text { injured players (all } \\
\text { injuries) } \\
\text { Number of acute } \\
\text { knee/ankle injuries } \\
\text { Number of overuse } \\
\text { injuries } \\
\text { Knee and ankle } \\
\text { injuries per } 1000 \\
\text { player hours }\end{array}$ & $\begin{array}{l}85 \\
18 \\
0.9\end{array}$ & $\begin{array}{l}156 \\
39 \\
1.8\end{array}$ & $\begin{array}{l}0.49(0.36 \text { to } 0.68) \\
0.51(0.39 \text { to } 0.66) \\
0.43(0.25 \text { to } 0.75) \\
0.53(0.35 \text { to } 0.81)\end{array}$ & $-0.1(10 \%)$ & 10 \\
\hline $\begin{array}{l}\text { Wedderkopp } \\
\text { (1999) }\end{array}$ & 137 & $\begin{array}{l}\text { Number of injuries } \\
\text { Injuries per } 1000 \mathrm{~h} \\
\text { practice } \\
\text { Injuries per } 1000 \mathrm{~h} \\
\text { game }\end{array}$ & $\begin{array}{l}14 \\
0.34 \\
4.68\end{array}$ & $\begin{array}{l}66 \\
1.17 \\
23.38\end{array}$ & 0.198 & $-0.26(26 \%)$ & 4 \\
\hline $\begin{array}{l}\text { Wedderkopp } \\
\text { (2003) }\end{array}$ & 163 & $\begin{array}{l}\text { Incidence of traumatic } \\
\text { injury } / 1000 \mathrm{~h} \text { practice } \\
\text { Incidence of traumatic } \\
\text { injury } / 1000 \mathrm{~h} \text { match }\end{array}$ & $\begin{array}{l}0.2 \\
2.4\end{array}$ & $\begin{array}{l}0.6 \\
6.9\end{array}$ & $\begin{array}{l}0.42 \text { when using ankle } \\
\text { disc compared with no } \\
\text { ankle disc training }\end{array}$ & $-0.11(11 \%)$ & 9 \\
\hline Hewett & 1263 & $\begin{array}{l}\text { Number of serious } \\
\text { knee injuries } \\
\text { Knee injury per } 1000 \\
\text { exposures } \\
\text { Non-contact injuries } \\
\text { per } 1000 \text { exposures }\end{array}$ & $\begin{array}{l}2 / 366 \\
0.12 \\
0\end{array}$ & $\begin{array}{l}10 / 463 \\
0.43 \\
0.35\end{array}$ & 0.25 (0.06 to 1.15$)$ & $-0.015(1.5 \%)$ & $\begin{array}{l}66 \text { (note these data } \\
\text { reflect serious } \\
\text { injuries; most were } \\
\text { season ending) }\end{array}$ \\
\hline Heidt & 300 & $\begin{array}{l}\text { Total number of } \\
\text { injured subjects } \\
\text { Total number of injuries }\end{array}$ & $\begin{array}{l}6 / 42 \\
7 / 42(16 \%)\end{array}$ & $\begin{array}{l}87 / 258 \\
91 / 258(35 \%)\end{array}$ & $0.42(0.2$ to 0.9$)$ & $\begin{array}{l}-0.20(20 \%) \\
-0.19(19 \%)\end{array}$ & 5 \\
\hline Grace & 580 & $\begin{array}{l}\text { Number of knee injuries } \\
\text { (diagnosed by doctor) } \\
\text { Number of concussions }\end{array}$ & $\begin{array}{l}42 / 330 \\
7 / 1179\end{array}$ & $\begin{array}{l}11 / 250 \\
2 / 357\end{array}$ & $\begin{array}{l}2.88 \\
1.05\end{array}$ & $\begin{array}{l}+0.083(+8.3 \%)^{*} \\
+0.0003(+0.03 \%)^{*}\end{array}$ & $\begin{array}{l}\text { Higher injury rate in } \\
\text { intervention group } \\
\text { Higher injury rate in }\end{array}$ \\
\hline $\begin{array}{l}\text { Macintosh } \\
\text { Webster }\end{array}$ & 700 & $\begin{array}{l}\text { Number of concussions } \\
\text { (diagnosed by doctor) } \\
\text { Number of injuries per }\end{array}$ & 1.25 & 2.4 & 0.52 & Insufficient data & $\begin{array}{l}\text { intervention group } \\
\text { Insufficient data }\end{array}$ \\
\hline Yang & $\begin{array}{l}1104354 \\
\text { athlete exposures } \\
\text { (19,728 athletes) }\end{array}$ & Lower extremity injury & $\begin{array}{l}\text { Unable to } \\
\text { calculate }\end{array}$ & $\begin{array}{l}\text { Unable to } \\
\text { calculate }\end{array}$ & $\begin{array}{l}0.91 \text { (0.72 to } 1.15 \text { ) } \\
\text { when use of all } \\
\text { protective equipment } \\
\text { compared with control }\end{array}$ & $9 \%$ & Insufficient data \\
\hline
\end{tabular}

$\mathrm{ACL}$, anterior cruciate ligament; NNT, number needed to treat; RR, relative risk.

${ }^{*}+$ indicates increased risk in intervention group.

In summary, there is limited evidence that eye goggles and knee pads can reduce the incidence of head and face $(\mathrm{RR}=0.52)^{12}$ and knee $(\mathrm{RR}=0.44)^{11}$ injuries, respectively, and there is currently no evidence to suggest that headgear $(\mathrm{RR}=1.05)^{17}$ and knee braces $(\mathrm{RR}=2.24)^{13}$ have a positive effect on injury prevention.

\section{Preseason conditioning}

Hewett et $a l^{19}$ used a preseason conditioning strategy to develop flexibility, strength, power and landing mechanics. Using a sample of female soccer, volleyball and basketball players, he found that 6 weeks of this preventive intervention (three sessions a week) decreased the number of serious knee injuries over the next sporting season. Although this study used a large sample size $(n=1263)$, it scored poorly on the quality scale $(<50 \%)$, and subjects entered into either the intervention or control group on a voluntary basis. Moreover, the effect of this strategy on other lower limb injuries is not clear.

Heidt et $a l^{15}$ carried out a similar study, but used a randomised controlled study design with moderate quality
(11/18), using a smaller group of female soccer players. The study randomised subjects to either a 7-week conditioning programme designed to improve sports-specific cardiovascular fitness, lower limb strength, flexibility and power or to a control group receiving no preseason intervention. A l-year (two seasons) follow-up showed that the injury rate of the conditioning group was significantly lower than that of the control group.

In summary, there is poor evidence from one cohort study and moderate evidence from one randomised controlled study that 6 weeks of preseason conditioning can significantly reduce injury rate in female athletes $\left(R R=0.25^{19}, R R=0.42^{15}\right)$.

\section{Injury prevention strategies throughout the playing season}

\section{Proprioceptive training}

Three studies ${ }^{14} 2122$ using cluster randomisation and scoring moderately (10/18) on the quality scoring scale examined the effectiveness of various balance-training protocols. Emery et al ${ }^{14}$ found that a home-based proprioceptive balance-training 


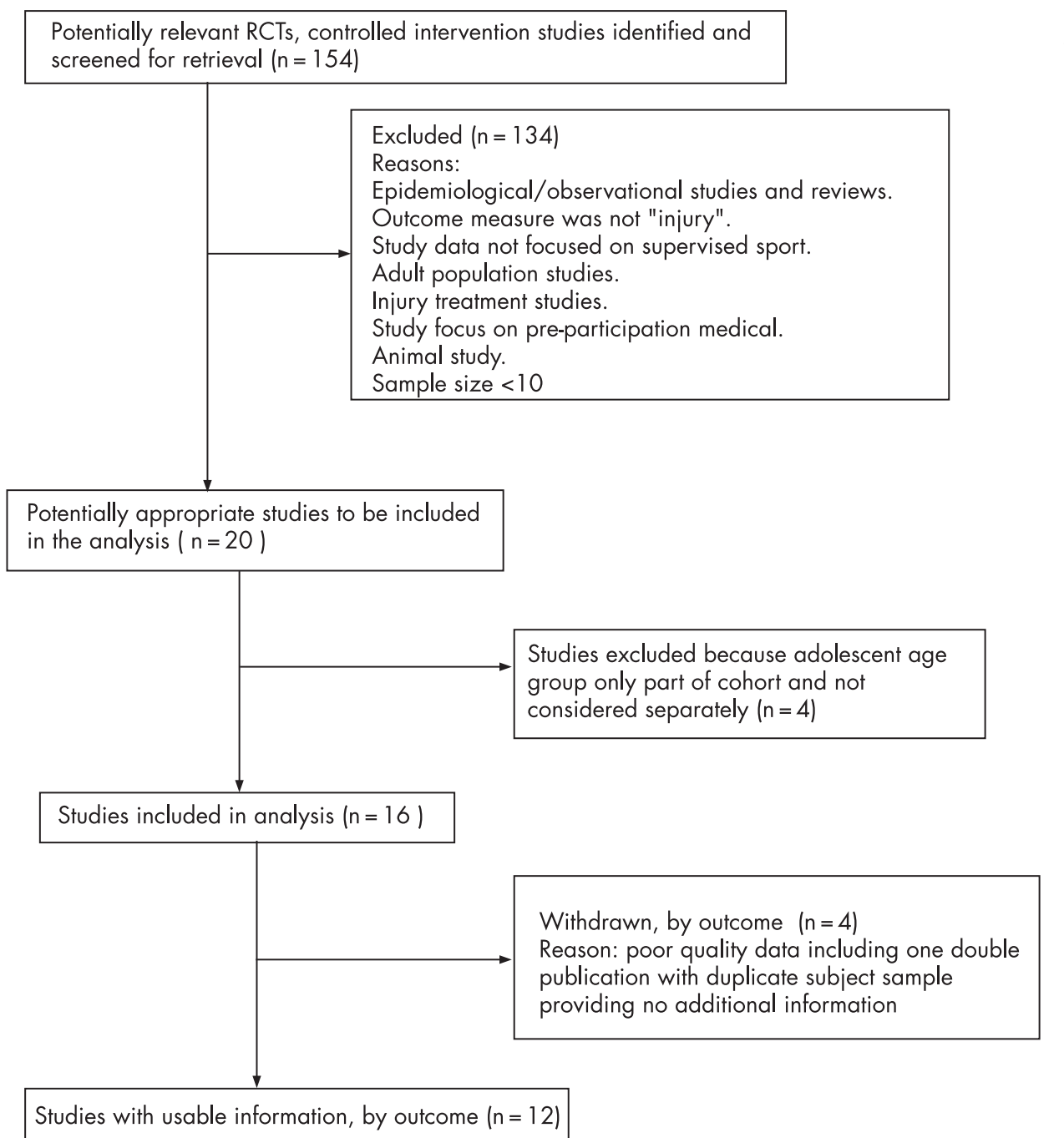

Figure 1 A systematic review of strategies to prevent injury in adolescent sport. RCT, randomised controlled trial.

Studies with usable information, by outcome $(n=12)$

programme (daily for 6 weeks, then weekly for a further 5 months) using a wobble board improved static and dynamic balance in healthy adolescents and reduced the incidence of self-reported injury over a 6-month period. Similarly, Wedderkopp et $a^{21}$ found that female handball players using an ankle disc in conjunction with functional strengthening at each practice session were less likely to be injured than a control group (training as normal). A follow-up study by the same group ${ }^{22}$ using similar methods and population provided evidence that the combination of ankle disc training and functional strengthening is more effective at reducing injury incidence than functional strengthening alone.

\section{Structured warm-up}

Three trials ${ }^{161820}$ of moderate quality studied the cumulative effect of using a range of injury-preventive strategies during the playing season. Olsen et al ${ }^{18}$ block-randomised handball clubs in Norway to either a control intervention (training as normal) or an intervention group that used a structured 20-min warm-up before each training session. The warm-up consisted of lower limb proprioception, strengthening exercises and technical training, with all athletes encouraged to maintain optimal lower limb alignment and control. This study, which scored highest on methodological quality rating (13/18), found that fewer knee and ankle injuries occurred in the intervention group during the one-season follow-up period. Furthermore, a prospective cohort study ${ }^{20}$ found that a structured warm-up emphasising strengthening, stretching, plyometrics and soccer-specific agility was significantly more effective than a traditional warm-up at reducing ACL injuries in female soccer players. A more generic preventive programme (including education, warm-up, cool-down, taping, rehabilitation, flexibility and stability) delivered in the l-year cohort study of Junge et $a l^{16}$ was also effective in reducing male soccer injuries.

In summary, there is moderate evidence that all the reviewed injury-prevention strategies carried out throughout the playing season prevented injury (RR 0.2-0.73, table 6).

\section{Quantitative data synthesis}

Tables 1 and 2 describe the quality scoring key and study quality scores respectively. These tables illustrate that there was no good quality study scoring 16 or more, but seven moderate studies scoring between 9 and 15, and five poor quality studies scoring less than 9 . There were several criteria that consistently limited the quality of studies: none of the included studies carried out allocation concealment, and only one was considered to have performed sufficient randomisation; however, six additional studies demonstrated acceptable "cluster randomisation".

We assessed the treatment effect by (1) considering preventive strategy in relation to the risk, type and severity of injuries, (2) considering the feasibility of replicating the intervention used, and (3) calculating the number needed to treat (NNT) to prevent one injury. Treatment effect in terms of NNT was calculated where there were sufficient data and is given in table 6. 


\section{DISCUSSION}

\section{Protective equipment Headgear}

Headgear is designed to attenuate the impact energy of an insult to the head. In this review, McIntosh and McCrory ${ }^{17}$ found an increase in the rate of head injury with the use of protective headgear. It may be that the type of material used in headguards cannot withstand the high impacts associated with collision sports. Alternatively the findings may reflect the competitive nature of sport and the potential influence of protective equipment on behaviour. It has been proposed that wearing pads or headguards can cause "risk compensation" or "risk homoeostasis" whereby athletes act in a riskier manner than usual because of the sense of increased protection. ${ }^{23} 24$ Although a recent case-controlled study $(\mathrm{n}=674)^{25}$ seems to refute this theory, finding no association between the use of protective equipment and risk-taking activity in children, the inclusion of younger children (8-18 years) may have led to bias.

The use of mouthguards is another commonly used preventive strategy in contact sports. Studies on adults have shown that mouthguards can prevent injury in rugby union ${ }^{26} 27$ and other contact sports. ${ }^{28}$ Similar studies on adolescents have been undertaken, but they failed to meet the inclusion criteria for the current review. High-quality studies are therefore required to make definitive conclusions on the effectiveness of headgear and mouthguards and their influence on risktaking behaviour in adolescents.

\section{Bracing}

We found an increase in injuries associated with the use of protective external bracing, whereas kneepad use was associated with a reduction in lower limb injury. ${ }^{11} 13$ Primarily, it must be noted that the included studies scored poorly on study quality rating, and both failed to use any form of randomisation. Brace use in all included studies was based purely on individual preference, therefore a number of other confounding factors may have contributed to the injury incidence. Indeed it has been suggested that subjects opting not to wear a brace are more likely to be risk takers, whereas "brace users" might be more risk adverse. ${ }^{29}$ Other personality traits-for example, type A personality or levels of exercise dependence-can also act as a precursor to sustaining injury, ${ }^{30}$ and although this conjecture may not explain the present results, it does highlight the importance of using adequate randomisation procedures in future studies.

Notwithstanding the methodological flaws, an increase in injury was associated with the use of protective bracing, which agrees with earlier reports. ${ }^{31}$ Although there is some evidence from cadaver studies that knee bracing does offer protection to knee ligaments under external load, ${ }^{31}{ }^{32}$ this effect may not carry over to the high-velocity, multidirectional forces encountered during sporting activity. Others have found that bracing can lead to increased muscle fatigue, ${ }^{33}$ and it has also been linked to decreased athletic performance, ${ }^{33}$ factors that may cumulate to increase the injury risk.

Pragmatists argue that the potential benefits of taping and bracing are related to enhancing sensorimotor control rather than providing mechanical constraint, but the evidence to support this remains contradictory. There is some evidence to show that knee bracing can enhance sensorimotor control in subjects with a history of knee injury, ${ }^{34}{ }^{35}$ but the effect is lessened with more demanding functional tasks, and the clinical benefits of such small changes have also been questioned. $^{35} \mathrm{~A}$ review by Beynnon et $a^{36}$ found that the application of an elastic bandage can enhance joint positional sense in knees with an ACL tear, and a cohort study also supports the use of knee bracing in preventing re-injury during skiing. ${ }^{37}$ Generally, however, the effects of bracing on sensorimotor control seem less definitive in healthy subjects, ${ }^{38}$ and a systematic review ${ }^{39}$ found no consistent evidence of effectiveness for knee bracing in reducing knee injury in adult and adolescent sports people. Further randomised studies must assess the effectiveness of bracing in preventing primary injury in adolescents.

\section{Preseason conditioning and preventive strategies continued throughout the playing season}

Conditioning programmes that include strength, flexibility, balance, and sport-specific fitness and technique training prevent lower limb injury. This benefit appears to be optimised when the preventive programme is continued throughout the playing season. This finding is consistent with adult studies that showed significant reductions in ankle sprain on introduction of preventive programmes in volleyball. ${ }^{40-42}$ Similarly preventive programmes in football (soccer) produced a 50$75 \%$ reduction in injuries in general $^{43}$ and a significant reduction in ACL injuries. ${ }^{44}$

Conversely our findings do not agree with a review of the impact of stretching on sports injury risk. ${ }^{45}$ Studies that focus on stretching alone or stretching plus warm-up and cool-down strategies-for example, a stretching protocol performed during pre-exercise warm-up-did not produce clinically meaningful reductions in risk of exercise-related injury in army recruits, ${ }^{46}{ }^{47}$ and half-time stretching exercises performed by high school footballers did not reduce the incidence of match injuries. ${ }^{48}$ Furthermore, research on running injuries ${ }^{49} 50$ indicates that injury incidence is not reduced by preventive strategies such as stretching, warm-up and cool-down. This could be explained by the pre-study practice of participants-that is, they were already undertaking some form of pre-exercise programme that included these aspects and therefore the intervention studied was not sufficiently different to demonstrate an effect change. An additional consideration may be that recreational and distance runners are not an equivalent population group, and caution should be exercised in extrapolating results to this setting.

It may be that the functional components of the preventive programme-that is, conditioning, proprioceptive balance training and skills training-are responsible for producing the physiological adaptations that help to prevent injury in the adolescent population.

In summary, we found that the evidence for using protective equipment-that is, bracing, taping and headgear-is inconclusive and hampered by confounding factors that are difficult to control for. There is poor evidence to support the protective effect of knee pads and eye goggles. However, there is significant and consistent evidence to support injury prevention strategies that include a combination of the following elements: preseason conditioning, functional training, education, strength, and proprioceptive balance training programmes that are continued throughout the playing season. The risk reduction is broadly similar for all strategies studied. The NNT to avoid an injury ranged from 4-10 for all injuries (table 6) to 66 for serious injury-that is, ACL injury. ${ }^{19}$ Clearly no "one value" for NNT can be deemed worthwhile. 9 However, it would seem acceptable that 10 adolescents should be trained in such a way as to avoid one minor injury. Similarly a training programme that could prevent a season-threatening, if not career-threatening, injury such as an ACL rupture with a NNT of less than 100 would normally be considered acceptable. Furthermore, the intervention programmes described could easily be reproduced and applied across many sports. A significant proportion of the programmes are probably current practice in many training sessions, and adaptation to include aspects such as proprioception does not carry a major educational or financial implication. 


\section{What is already known on this topic}

- Sport is the main cause of injury in adolescents.

- Adult studies have identified that injury can be prevented by using protective equipment and improving fitness, flexibility and balance.

- However, injury-prevention strategies that focus specifically on the adolescent age group have not been reviewed.

\section{What this study adds}

- There is significant and consistent evidence in the literature to support the use of injury-prevention strategies in adolescents that include preseason conditioning as well as functional training, education, strength and balance programmes that are continued throughout the playing season.

- The evidence for protective equipment in injury prevention in adolescents is inconclusive and requires further assessment.

\section{CONCLUSION}

The development and application of injury prevention strategies that focus on preseason conditioning, functional training, education, proprioceptive balance training and sport-specific skills, which should be continued throughout the sporting season, are effective. The evidence for protective equipment in injury prevention is inconclusive and requires further assessment.

\section{ACKNOWLEDGEMENTS}

We thank Diurmuid Kennedy and Angela Thompson, Queens University Medical Library, for advice and help with database searches, and Domhnall MacAuley for editorial advice.

\section{Authors' affiliations}

Liz Abernethy, Musgrave Park Hospital, Belfast, Northern Ireland Chris Bleakley, Department of Health and Rehabilitation Sciences Research Institute, University of Ulster, Jordanstown, Northern Ireland

Competing interests: None.

\section{REFERENCES}

1 Emery C. Risk factors for injury in child and adolescent sport: a systematic review of the literature. Clin J Sport Med 2005;13:256-68.

2 Abernethy L, MacAuley D. Impact of school sports injury. Br J Sports Med 2003:37:354-5.

3 Lidqvist KS, Timpka T, Bjurulf P. Injuries during leisure physical activity in a Swedish municipality. Scand J Soc Med 1996;24:282-92.

4 Lenaway DD, Ambler AG, Beaudoin DE. Am J Prev Med 1992;8:193-8.

5 Drawer F, Fuller CW. Propensity for osteoarthritis and lower limb joint pain in retired professional soccer players. Br J Sports Med 2001;35:402-8.

6 MacKay M, Scanlan A, Olsen L. Sports and recreational injury prevention strategies: systematic review and best practices: executive summary. Vancouver, BC: BC Injury Research and Prevention Unit, 2001

7 Grimmer KA, Jones D, Williams J. Prevalence of adolescent injury from recreational exercise: an Australian perspective. J Adolesc Health 2000;27:1-6.

8 Ekland E, Heian F, Hagan KB, et al. Exercise to improve self esteem in children and young people. Cochrane Database Syst Rev, 2004, Issue 1, CD003683.

9 Herbert RD. How to estimate treatment effects from reports of clinical trials. II. Dichotomous outcomes. Aust J Physiother 2000;46:309-13.

10 Moher D, Cook DJ, Eastwood S, et al. Improving the quality of reports of metaanalyses of randomised controlled trials: the QUOROM statement. Quality of Reporting of Meta-analyses. Lancet 1999;354:1896-900.
11 Yang J, Marshall SW, Bowling JM, et al. Use of discretionary protective equipment and rate of lower extremity injury in high school athletes. Am J Epidemiol 2005;161:511-19.

12 Webster DA, Bayliss GV, Spadaro JA. Head and face injuries in scholastic women's lacrosse with and without eyewear. Med Sci Sports Exerc 1999;31:938-41.

13 Grace TG, Skipper BJ, Newberry JC, et al. Prophylactic knee braces and injury to the lower extremity. J Bone Joint Surg [Am] 1988;70:422-7.

14 Emery CA, Cassidy JD, Klassen TP, et al. Rowe BH. Effectiveness of a homebased balance-training program in reducing sports-related injuries among healthy adolescents: a cluster randomized controlled trial, CMAJ 2005;172:749-54.

15 Heidt RS, Sweeterman MD, Carlonas RL. Avoidance of soccer injuries with preseason conditioning. Am J Sports Med 2000;28:659-62.

16 Junge A, Rosch D, Peterson L, et al. Prevention of soccer injuries: a prospective intervention study in youth amateur players. Am J Sports Med 2002;30:652-9.

17 McIntosh AS, McCrory P. Effectiveness of headgear in a pilot study of under 15 rugby union football. Br J Sports Med 2001;35:167-9.

18 Olsen OE, Myklebust G, Engebretsen L, et al. Exercises to prevent lower limb injuries in youth sports: cluster randomised controlled trial. BMJ 2005;330:449.

19 Hewett TE, Lindenfield TN, Riccobene JV, et al. The effect of neuromuscular training on the incidence of knee injury in female athletes. Am J Sports Med 1999:27:699-705.

20 Mandelbaum BR, Silvers HJ, Watanabe DS, et al. Effectiveness of a neuromuscular and proprioceptive training program in preventing anterior cruciate ligament injuries in female athletes: 2-year follow-up. Am J Sports Med 2005;33:1003-10.

21 Wedderkopp N, Kaltoft B, Rosendahl M, et al. Prevention of injuries in young female players in European team handball. Scand J Med Sci Sports 1999:9:41-7.

22 Wedderkopp N, Kaltoft M, Holm R, et al. Comparison of two intervention programmes in young female players in European handball: with and without ankle disc. Scand J Med Sci Sports 2003;13:371-5.

23 Mclntosh AS. Risk compensation, motivation, injuries and biomechanics in competitive sport. Br J Sports Med 2005;39:2-3.

24 Hagel B, Meeuwisse W. Risk compensation: a "side effect" of sport injury prevention? Clin J Sport Med 2004:14:193-6.

25 Pless IB, Magdalinos H, Hagel B. Risk compensation behaviour in children: myth or reality? Arch Pediatr Adolesc Med 2006;160:610-14

26 Quarrie KL, Gianotti SM, Chalmers DJ, et al. An evaluation of mouthguard requirements and dental injuries in New Zealand Rugby Union. Br J Sports Med 2005;39:650-4.

27 Jennings DC. Injuries sustained by users and non users of gum shields in local rugby union. Br J Sports Med 1990;24:159-65.

28 Onyesco CO, Adegbesan OA. Knowledge and attitudes of coaches of secondary school athletes in Ibadan, Nigeria regarding oro-facial injuries and mouthguard use by the athletes. Dental Traumatol 2003;19:204-8

29 Sterett WI, Briggs KK, Farley T, et al. Effect of functional bracing on knee injury in skiers with anterior cruciate ligament reconstruction. A prospective cohort study. Am J Sports Med 2006;34:1581-5.

30 Ekenman I, Hassmen P, Koivula N, et al. Stress fractures of the tibia: can personality traits help us detect the injury-prone athlete? Scand J Med Sci Sports 2001;11:87-95.

31 Tietz CC, Hermanson B, Kronmal R, et al. Evaluation of the use of braces to prevent injury to the knee in college football players. J Bone Joint Surg 1987;69:2-8

32 Paulos LE, Cawley PW, France EP. Impact biomechanics of lateral knee bracing The anterior cruciate ligament. Am J Sports Med 1991;19:337-42.

33 Hinterwimmer S, Graichen $\mathrm{H}$, Baumgart R, et al. Influence of a mono-centric knee brace on the tension of the collateral ligaments in knee joints after sectioning of the anterior cruciate ligament: an in vitro study. Clin Biomech 2004; 19:719-25.

34 Styf $\mathrm{J}$. The effects of functional knee bracing on muscle function and performance. Sports Med 1999;28:77-81.

35 Kuster MS, Grob K, Kuster M, et al. The benefits of wearing a compression sleeve after ACL reconstruction. Med Sci Sports Exerc 1999;31:368-71.

36 Beynnon BD, Good L, Risberg MA. The effect of bracing on proprioception of knees with anterior cruciate ligament injury. J Orthop Sports Phys Ther 2002;32:11-15.

37 Birmingham TB, Kramer JF, Kirkley A, et al. Knee bracing after ACL reconstruction: effects on postural control and proprioception. Med Sci Sports Exerc 2001;33:1253-8.

38 Kaminski TW, Perrin DH. Effect of prophylactic knee bracing on balance and joint position sense. J Athl Train 1996;31:131-6.

39 Thacker SB, Stroup DF, Branche CM, et al. Prevention of knee injuries in sports. A systematic review of the literature. J Sports Med PhysFitness 2003;43:165-79.

40 Bahr R, Lian O. A two-fold reduction in the incidence of acute ankle sprains in volleyball. Scand J Med Sci Sports 1997;7:172-7.

41 Stasinopoulos D. Comparison of three preventive methods in order $t$ reduce the incidence of ankle inversion sprains among female volleyball players. $\mathrm{Br} J$ Sports Med 2004;38: 182-5.

42 Verhagen E, van der Beek A, Twisk J, et al. The effect of proprioceptive balance board training programme for prevention of ankle sprain: a prospective controlled trial. Am J Sports Med 2004;32:1385-93.

43 Ekestrand J, Gillquist J. Prevention of sport injuries in football players. Int J Sports Med 1984;5:140-4.

44 Caraffa A, Cerulli G, Projetti M, et al. Prevention of anterior cruciate ligament injuries in soccer: a prospective controlled study of proprioceptive training. Knee Surg Sports Traumatol Arthrosc 1996;4:19-21. 
45 Thacker SB, Gilchrist J, Stroup DF, et al. The impact of stretching on sports injury risk: a systematic review of the literature. Med Sci Sports Exerc 2004;36:371-8.

46 Pope RP, Herbert RD. Effects of flexibility and stretching on injury risk in army recruits. Aust J Physiother 1998;44:165-72.

47 Pope RP, Herbert RD, Kirwan JD, et al. A randomized trial of preexercise stretching for prevention of lower-limb injury. Med Sci Sports Exerc 2000;32:271-7.
48 Bixler B, Jones RL. High-school football injuries: effects of a post-halffime warmup and stretching routine. Fam Pract Res J 1992;12:131-9.

49 van Mechelen W, Hiobil $\mathrm{H}$, Kemper $\mathrm{HC}$, et al. Prevention of running injuries by warm up, cool down, and stretching exercises. Am J Sports Med 1993;21:711-19.

50 Yeung EW, Yeung SS. A systematic review of interventions to prevent lower limb soft tissue running injuries. Br J Sports Med 2001;35:383-9.

\section{BMJ Clinical Evidence-Call for contributors}

BMJ Clinical Evidence is a continuously updated evidence-based journal available worldwide on the internet which publishes commissioned systematic reviews. BMJ Clinical Evidence needs to recruit new contributors. Contributors are healthcare professionals or epidemiologists with experience in evidence-based medicine, with the ability to write in a concise and structured way and relevant clinical expertise.

Areas for which we are currently seeking contributors:

- Secondary prevention of ischaemic cardiac events

- Acute myocardial infarction

- MRSA (treatment)

- Bacterial conjunctivitis

However, we are always looking for contributors, so do not let this list discourage you.

\section{Being a contributor involves:}

- Selecting from a validated, screened search (performed by in-house Information Specialists) valid studies for inclusion.

- Documenting your decisions about which studies to include on an inclusion and exclusion form, which we will publish.

- Writing the text to a highly structured template (about 1500-3000 words), using evidence from the final studies chosen, within 8-10 weeks of receiving the literature search.

- Working with BMJ Clinical Evidence editors to ensure that the final text meets quality and style standards.

- Updating the text every 12 months using any new, sound evidence that becomes available. The $B M J$ Clinical Evidence in-house team will conduct the searches for contributors; your task is to filter out high quality studies and incorporate them into the existing text.

- To expand the review to include a new question about once every 12 months.

In return, contributors will see their work published in a highly-rewarded peer-reviewed international medical journal. They also receive a small honorarium for their efforts.

If you would like to become a contributor for BMJ Clinical Evidence or require more information about what this involves please send your contact details and a copy of your CV, clearly stating the clinical area you are interested in, to CECommissioning@bmigroup.com.

\section{Call for peer reviewers}

BMJ Clinical Evidence also needs to recruit new peer reviewers specifically with an interest in the clinical areas stated above, and also others related to general practice. Peer reviewers are healthcare professionals or epidemiologists with experience in evidence-based medicine. As a peer reviewer you would be asked for your views on the clinical relevance, validity and accessibility of specific reviews within the journal, and their usefulness to the intended audience (international generalists and healthcare professionals, possibly with limited statistical knowledge). Reviews are usually 1500-3000 words in length and we would ask you to review between 2-5 systematic reviews per year. The peer review process takes place throughout the year, and our turnaround time for each review is 10-14 days. In return peer reviewers receive free access to BMJ Clinical Evidence for 3 months for each review.

If you are interested in becoming a peer reviewer for BMJ Clinical Evidence, please complete the peer review questionnaire at www.clinicalevidence.com/ceweb/contribute/peerreviewer.jsp 